\title{
Practical Story: Real People, Real Urine, Unreal UTI
}

\section{Charlene Offiong ${ }^{1}$, Barbara Trautner ${ }^{2}$, Ed Septimus ${ }^{4}$, Kristi Kuper ${ }^{3}$, Tolulope Olumuyiwa ${ }^{1}$}

${ }^{1}$ Houston Health Department, Houston, Texas, United States, ${ }^{2}$ Baylor College of Medicine, Houston, Texas, United States, ${ }^{3}$ Vizient Inc, Houston, Texas, United States, ${ }^{4}$ Harvard Medical School , Boston, Massachusetts, United States

Objective

- To describe findings from the joint collaborative between the Houston Health Department and Houston-based hospitals

- To promote cross sectional partnerships and collaborations across health agencies

\section{Introduction}

Asymptomatic Bacteriuria (ASB) is defined as the presence of bacteria in the urine of a patient without signs or symptoms of a urinary tract infection (UTI). It is one of the most common reasons for inappropriate antibiotic use in hospitalized patients. Without efforts to check inappropriate use, our communities could see increased numbers of highly resistant bacterial pathogens contributing to the public health threat of antimicrobial resistance. Treatment itself may be

associated with subsequent antimicrobial resistance, adverse drug effects, and cost. The Houston Health Department (HHD) has made it a priority to address antibiotic resistance and stewardship by working collaboratively with members of the healthcare community to address this patient safety issue. As such HHD, in conjunction with infectious diseases experts from the HHD Antimicrobial Stewardship Executive Committee formed a joint learning collaborative to work on an asymptomatic bacteriuria stewardship project. The goal of the project was to engage with healthcare professionals across facilities within the Houston area to work collaboratively to help reduce unnecessary testing and treatment of ASB.

\section{Methods}

The project is a joint learning collaborative between HHD and selected acute care facilities within the City of Houston. Space was limited to no more than 8 hospitals and enrollment occurred on a first come, first serve basis. Activities conducted as part of the project included a Project Launch meeting held at HHD that as attended by participants, education by project subject matter experts (SMEs), monthly calls with SMEs to provide case-based feedback and intervention tools. The project launch meeting included a brief overview of the project, review of an asymptomatic bacteruria algorithm (referred to as "Kicking UTI" algorithm), instructions on how to classify cases, project timeline and plan implementation. The project timeline was 8 months (this included the Kick off Meeting in month 1, data collection in months 2-4, intervention period during months 5-7, preliminary report in month 4 and final report at month 8. Participants were encouraged to do the interventions in one area (e.g. Emergency Room or a single ward) vs. institution wide. Intervention tools provided included a case classification form with instructions, an electronic form that was pre-formatted for local data collection (using Microsoft Access), and project launch worksheet. The project launch worksheet asked participants about their goals for the project, areas of desired improvements, units/wards to be targeted and key members of the project (e.g. executive champion, project champion, and active participants) at their facility. The agenda for the monthly calls included discussing data collection (i.e. number of cases classified), SME review of challenging cases, and utilization of education and project tools. Finally, onsite visits by the SMEs and HHD representatives were offered to participants to increase local site engagement.

\section{Results}

Seven acute care hospitals and 1 rehabilitation facility were enrolled in the collaborative. Participants from the institutions included 11 clinical pharmacists and one nurse. Half of the participants originally targeted emergency departments (ED). The remaining participants conducted interventions on the medical/surgical wards and one facility conducted interventions on the brain injury floor. Additional activities were adapted and added throughout the program period. These included: 1) choice of ward versus ED 2) targeted providers (working with mid-level providers to discourage standard urine testing in the emergency department) and 3) strategies for education. Strategies for education included utilizing nurse practitioners to educate nurses, designing project marketing tools (flyers, posters, and pocket cards), pharmacy rounds, resident orientation and one-to-one education. Site visits were conducted at 3 facilities and included a range of interventions from 1:1 peer to peer discussions to large presentations to medical staff. Outcomes for 3 sites included Pre-project ASB treatment rates of $61 \%$

ISDS Annual Conference Proceedings 2019. This is an Open Access article distributed under the terms of the Creative Commons AttributionNoncommercial 3.0 Unported License (http://creativecommons.org/licenses/by-nc/3.0/), permitting all non-commercial use, distribution, and reproduction in any medium, provided the original work is properly cited. 
ISDS 2019 Conference Abstracts

and Post project ASB treatment rates of $24 \%$, representing a $37 \%$ decrease in ASB treatment for these sites. In addition, two health systems that participated in the study utilized the information obtained from the project to work with their laboratory departments to change testing practices by increasing the threshold of urine white blood cells required in the sample before reflex to testing for the presence of bacteria.

\section{Conclusions}

This project showed that collaboration between a city Health Department and local institutions can be successful in reducing the overtreatment of ASB. HHD facilitated collaboration, assisted with eliminating barriers to knowledge sharing and served as a partner in setting transparent goals. A cross disciplinary approach to promoting patient safety indirectly lead to gains in public health. In person interaction between the Health Department, SMEs, and representatives from local facilities helped to increase engagement throughout the project. The results of this project will be shared on the Health Department website as a way of forging community practices and stretching the role of the health department to serve as an advocate for public health and patient safety. Future projects would benefit from having increased participation from facillity stakeholders to promote institutional sustainability.

ISDS Annual Conference Proceedings 2019. This is an Open Access article distributed under the terms of the Creative Commons AttributionNoncommercial 3.0 Unported License (http://creativecommons.org/licenses/by-nc/3.0/), permitting all non-commercial use, distribution, and reproduction in any medium, provided the original work is properly cited. 